\title{
Effect of Organic Solvents on the Electrical Properties of a Neat Epoxy Resin System
}

\author{
Jae-Jun Park ${ }^{+}$ \\ Department of Electrical and Electronic Engineering, Joongbu University, Geumsan 312-702, Korea
}

Received January 17, 2012; Revised February 15, 2012; Accepted February 20, 2012

\begin{abstract}
The effect of organic impurities on the electrical properties of a neat epoxy resin was studied. $0.05,0.5$ and $1.0 \mathrm{phr}$ of iso-propyl alcohol (IPA) and methylene chloride (MC) mixture (50/50 wt\%) were used as impurities. The current density, volume resistance and impedance characteristics of the epoxy/IPA/MC systems were measured with a high voltage source meter and broadband dielectric spectroscopy. Glass transition temperature (Tg) was measured by a differential scanning calorimetry (DSC) and it was found that Tg decreased slightly with increasing IPA/MC content. It was also found that $\mathrm{Tg}$ values of the epoxy systems with various IPA/MC contents were closely related to the current density, volume resistance and impedance characteristics.
\end{abstract}

Keywords: Impurity, Organic solvent, Current density, Impedance, Epoxy

\section{INTRODUCTION}

Nanotechnology becomes has recently witnessed a surge in popularity on the global scale as a research field . Research on generators and rotators operated in high voltage applications also require nanoscience and nanotechnology due to a need for high insulation strength, thermal stability, mechanical strength, in the insulative materials used, and it is expected that epoxy nanocomposites will become a favorable choice for such applications. However, Nano-sized filler aggregation the during mixing process makes it very difficult to prepare epoxy inorganic filler nanocomposite. This problem must be solved to modify the electrical insulation and mechanical strength of the nanocomposites [1-3].

Many researchers [4-6] have reported that electrical, thermal and mechanical properties of epoxy resin were improved by the addition of layered silicate or silica. According to the Tanaka's results [4], mechanical strength properties of epoxy nanocomposite such as tensile, bending, elastic, and impact strength

${ }^{\dagger}$ Author to whom all correspondence should be addressed: E-mail: jjpark@joongbu.ac.kr

Copyright $@ 2012$ KIEEME. All rights reserved.

This is an open-access article distributed under the terms of the Creative Commons Attribution Non-Commercia

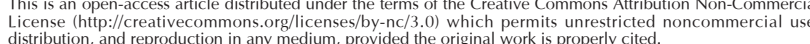

increase by 1.5 3 times compared to those of a neat epoxy resin, and thermal properties and expansion coefficients also improve. Electrical properties such as dc conductivity, interfacial polarization, partial discharge, tracking resistance, and permittivity also become more favorable . Imai [5] et al. compared the electrical breakdown strength of neat epoxy resin with those of epoxy/ silica nanocomposites or microcomposites. They reported that electrical breakdown strength of nanocomposites was far higher than that of pure epoxy and that a silane coupling agent reinforced the interfacial strength between epoxy resin and silica particles. Fuse [6] et al. showed that dibutylhydroxytoluene (BHT) as an impurity negatively effects a sample's electrical properties by acting as a carrier.

However, when inorganic filler is incorporated into an epoxy resin, the viscosity becames too high. So it is very difficult to remove bubbles from the epoxy/filler mixture and to inject the viscous mixture into a mould during the curing process. Therefore in order to decrease the viscosity, plasticizers or organic solvents must be introduced to the epoxy/filler nanocomposites during the the moulding process for the easy removal bubbles after injection into a mould. However, if the organic solvent is not completely removed, they maybe impurities that negatively affect the electrical, mechanical and thermal properties of the epoxy nanocomposite would be negatively . In this study, the effect of iso-propyl alcohol (IPA) and methylene chloride (MC) as impuri- 


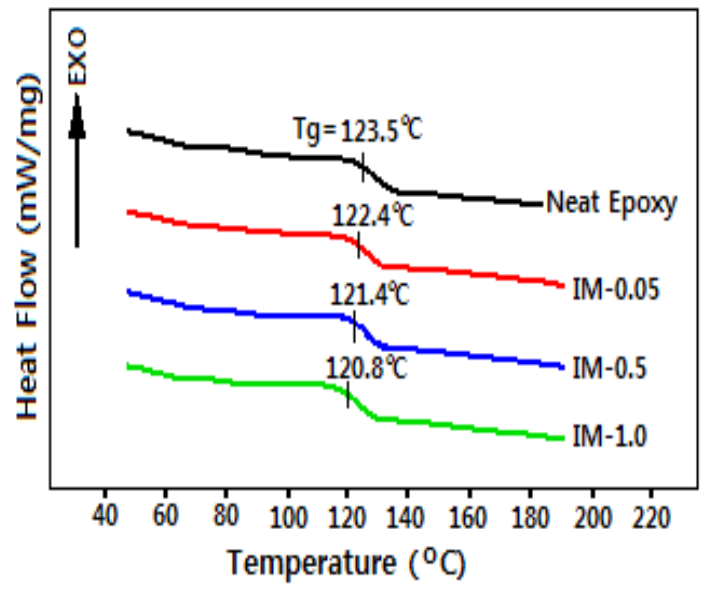

Fig. 1. Glass transition temperature (Tg) of the cured epoxy/IPA/MC systems obtained from DSC curves at a heating rate of $10^{\circ} \mathrm{C} / \mathrm{min}$.

ties on the electrical properties of neat epoxy was examined.

\section{EXPERIMENTS}

Bisphenol-A type epoxy resin was purchased from Jungdo E\&P Co. under the trade name of EXR225. The viscosity was $6,000 \sim 8,500 \mathrm{cps}$ at $25^{\circ} \mathrm{C}$ and its molecular weight was $182 \sim 186$. The curing agent was 3- or 4-methyl-1,2,3,6-tetrahydrophthalic anhydride (Me-THPA) whose trade name was HN-2200 (Hitachi Chem. Co., Japan), and a tertiary amine type accelerator was benzyl-dimethyl amine was also employed (BDMA, Kukdo Chem. Co. Korea). HPLC grade IPA and MC were purchased from GFS chemicals Inc.

80parts-per-hundred(phr) epoxy base resin Me-THPA and BDMA (0.9 phr) was mixed by mechanical stirrer for 20 minutes in a vacuum oven in order to remove bubbles. In order to study the effect of organic solvents on the electrical properties of neat epoxy , 0.05, 0.5 and $1.0 \mathrm{phr}$ of IPA/MC (50/50 wt\%) mixture was well mixed into the epoxy mixture by mechanical stirrer for 5 minutes and shear mixed with a 3-roll mill in order to remove bubbles. The samples were marked IM-0.05, IM-0.5 and IM-1.0, respectively. Then they were cured at $120^{\circ} \mathrm{C}$ for $2 \mathrm{hr}$ and postcured at $150^{\circ} \mathrm{C}$ for $2 \mathrm{hr}$, and then cooled slowly at a rate of $-0.5^{\circ} \mathrm{C} /$ min to room temperature to prevent internal stress.

The Electrical properties of the samples were measured by high voltage source meter (Keithley 2410) in an oven. Dielectric properties were estimated by broadband dielectric spectroscopy system using a Solartron SI1260 impedance analyzer. The frequency range was $10^{-2} \sim 10^{6} \mathrm{~Hz}$ and temperature range was $30 \sim 170^{\circ} \mathrm{C}$.

Differential scanning calorimetry (DSC) analysis was performed by a MDSC2910 (TA Instrument Ltd.). An aluminum pan containing $5 \mathrm{mg}$ of the cured sample was placed in the DSC cell the temperature of which was increased at a rate of $10^{\circ} \mathrm{C} / \mathrm{min}$ in a nitrogen flow at a rate of $60 \mathrm{ml} / \mathrm{min}$.

\section{RESULTS AND DISCUSSION}

Because glass transition temperature ( $\mathrm{Tg}$ ) of a polymer is closely related to polymer chain structure properties such as backbone, branching, and degree of crosslink, it should be examined in order to investigate the electrical properties of the polymeric materials. Figure 1 show the DSC curves for the cured neat

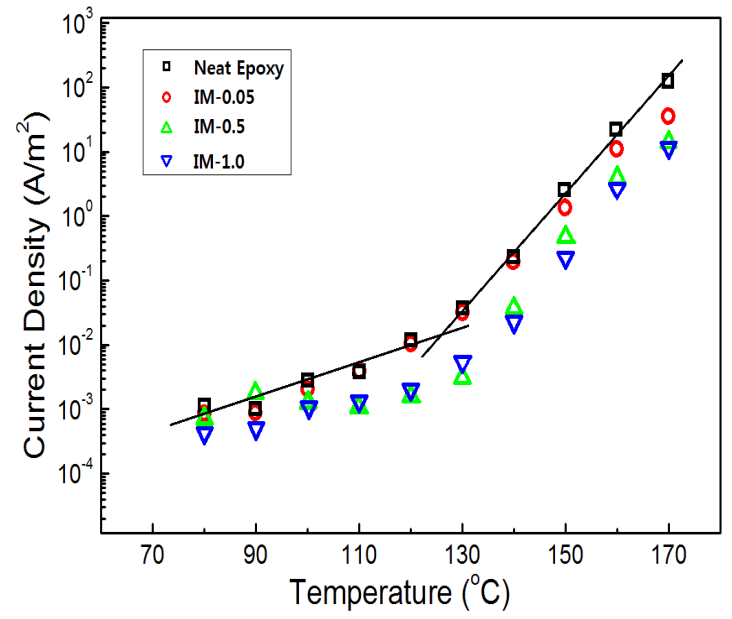

Fig. 2. Current density with respect to temperature for epoxy systems with various IPA/MC contents.

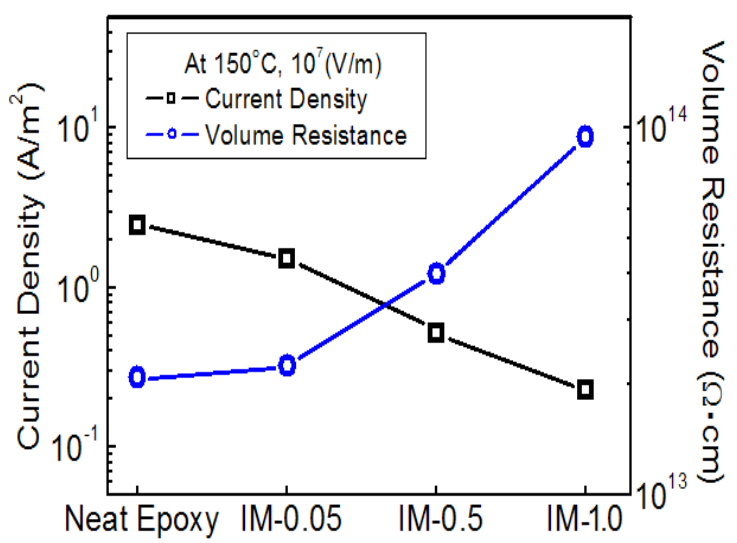

Fig. 3. Current density and volume resistance for epoxy systems with various IPA/MC contents.

epoxy resin and epoxy/IPA/MC systems at a heating rate of $10^{\circ} \mathrm{C}$ /min. All curves show no exothermic heat above Tg which means that these systems are completely cured with no remaining unreacted functional groups. $\mathrm{Tg}$ of the neat epoxy resin was $123.5^{\circ} \mathrm{C}$ which decreased slightly with increasing IPA/MC content. Which implies that IPA/MC acted as plasticizers in the neat epoxy resin through disturbance of the reaction between epoxide groups in the epoxy resin and hydroxyl groups in the curing agent. Therefore, many end-chains were generated and $\mathrm{Tg}$ decreased with the increasing IPA/MC content. However, the decreasing effect on Tg was very little.

Figure 2 showed current density depending on increasing temperature for epoxy systems with various levels of IPA/MC content. All the current density values were measured in an electric field of $10^{7} \mathrm{~V} / \mathrm{m}$. The current density for each system had two regions with two linear expressions of different slopes and inflection points around $120 \sim 130^{\circ} \mathrm{C}$. These were plotted from the scattered data for each system using the least square method. For example, the slopes of the two lines for the neat epoxy resin in Fig. 2 were 0.019 and 0.073 with an inflection point at $126.3^{\circ} \mathrm{C}$. The points for IM-0.05, IM-0.5 and IM-1.0 were 124.1, 123.4, and $122.8^{\circ} \mathrm{C}$, respectively, and it was found that these values were related to the Tg values in Fig. 1. Current density increased slowly with increasing temperature in the glass state under Tg, and the slope increased steeply in the rubbery state over Tg. This was 


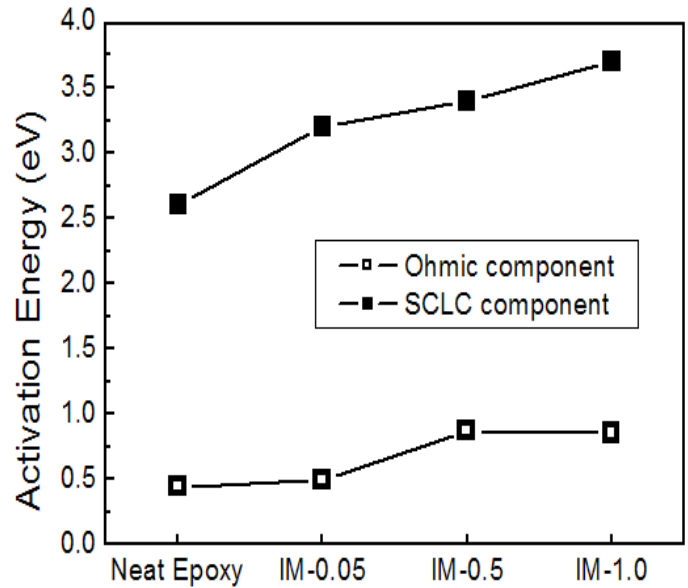

Fig. 4. Activation energy for Ohmic and SCLC components obtained from the data in Fig. 2.

due to the fact that the free volume in the epoxy resin abruptly increased over $\mathrm{Tg}$ so that epoxy polymer end-chains could easily move. That is to say, the conduction mechanism of the current density was changed at the inflection points from an Ohmic component to space charge limited current (SCLC) component [8].

Figure 3 shows the current density and volume resistance for epoxy systems with various IPA/MC contents, which were measured in an electric field of $10^{7} \mathrm{~V} / \mathrm{m}$ at $150^{\circ} \mathrm{C}$. As the IPA/MC content increased, the current density decreased and the volume resistance increased. It meant that IPA and MC interrupted the conduction of free electrons in the neat epoxy resin. It was confirmed by the estimation of the activation energy which is the energy level barrier that a free electron in an atom must overcome. The current process followed the Arrhenius law $[9,10]$, as expressed in Eq.(1):

$$
\mathrm{I}=\mathrm{I}_{0} \exp (-\mathrm{E} / \mathrm{kT})
$$

where, $I_{0}$ is a pre-exponential factor, $\mathrm{E}$ is the activation energy, $\mathrm{k}$ is Boltzman's constant $\left(8.617 \times 10^{-5} \mathrm{eV} / \mathrm{K}\right)$, and $\mathrm{T}$ is absolute temperature. To determine E, Eq.(1) was converted to Eq.(2) and the relationship between -ln I and $1 / \mathrm{T}$ is plotted using the current density curves in Fig. 2.

$$
-\ln \mathrm{I}=\ln \mathrm{I}_{0}+\mathrm{E} / \mathrm{kT}
$$

The relationships between -ln I and 1/T for the two regions for the neat epoxy resin were expressed as follows:

$$
\begin{aligned}
& -\ln \mathrm{I}=-7.66+5.11 \times 10^{3} / \mathrm{T},\left(80^{\circ} \mathrm{C}<\mathrm{T}<120^{\circ} \mathrm{C}\right) \\
& -\ln \mathrm{I}=-71.7+30.2 \times 10^{3} / \mathrm{T},\left(130^{\circ} \mathrm{C}<\mathrm{T}<170^{\circ} \mathrm{C}\right)
\end{aligned}
$$

The activation energies for the Ohmic component and SCLC component were calculated from each slope in Eq.(3) and (4). The values for other epoxy/IPA/MC systems were also obtained by using the same procedure and are displayed in Fig. 4 . As the

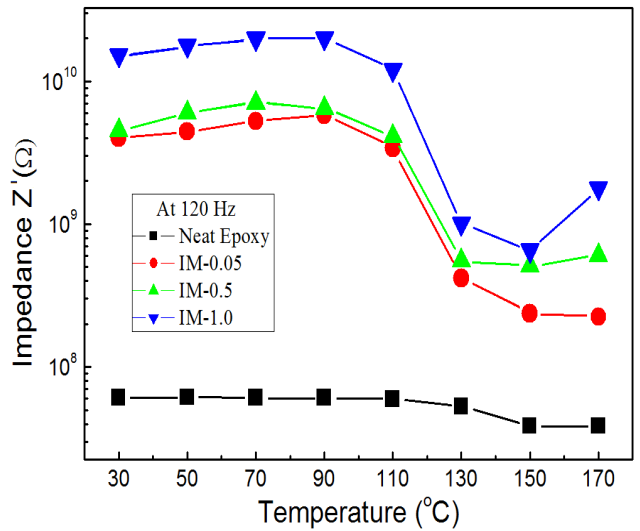

Fig. 5. Impedance spectroscopy varying with on temperature for epoxy systems with various IPA/MC contents.

expected, activation energy increased with increasing IPA/MC content and the activation for the Ohmic component in the lower temperature region was lower than that for the SCLC component.

Figure 5 shows impedance spectroscopy according to temperature for epoxy systems with various IPA/MC contents. In general, the complex impedance, $Z$ has two components: the real component, $Z^{\prime}$ and imaginary component, $Z^{\prime \prime}$ [11]. In this study, $Z^{\prime}$ was the parallel impedance in the equivalent circuit of the systems. All Z' values dramatically decreased at about $120 \sim 130^{\circ} \mathrm{C}$. It was also illustrated by the Tg values of Fig. 1. That is to say, epoxy polymer end-chains could easily move in the rubbery state.

\section{SUMMARY}

The effect of iso-propyl alcohol (IPA) and methylene chloride (MC) as impurities on the electrical properties of neat epoxy was studied. $\mathrm{Tg}$ of the neat epoxy resin was $123.5^{\circ} \mathrm{C}$ which it decreased slightly with increasing IPA/MC content. This temperature affected the current density, volume resistance and impedance of the epoxy/IPA/MC systems. The current density had two regions with two linear expressions having different slopes with inflection points around $120 \sim 130^{\circ} \mathrm{C}$ and $Z^{\prime}$ values also dramatically decreased in that temperature range. As expected, activation energy increased with increasing IPA/MC content and the activation for the Ohmic component in the lower temperature region was lower than that for the SCLC component.

\section{ACKNOWLEDGMENT}

This work was supported by Joongbu University (2011).

\section{REFERENCES}

[1] Y. S. Cho, M. J. Shim and S. W. Kim, Mater. Chem. Phys. 66, 70 (2000) [DOI: 10.1016/S0254-0584(00)00272-8].

[2] R. Sarathi, R. K. Sahu and P. Rajeshkumar, Mater. Sci. Eng.: A 445, 567 (2007) [DOI: 10.1016/j.msea.2006.09.077].

[3] J. J. Park and J. Y. Lee, IEEE Trans. Dielectr. Electr. Insul. 17, 1516 (2010) [DOI: 10.1109/TDEI.2010.5595553].

[4] T. Tanaka, G. C. Montanari and R. Mülhaupt, IEEE Trans. Dielectr. Electr. Insul. 11, 763 (2004) [DOI: 10.1109/ TDEI.2004.1349782].

[5] T. Imai, F. Sawa, T. Ozaki, T. Shimizu, R. Kido, M. Kozako and T. 
Tanaka, Proc. of 2005 Int. Sym. on Elec. Insul. Mat., Kitakyusyu, Japan, pp. 239-242 (2005) [DOI: 10.1109/ISEIM.2005.193387].

[6] N. Fuse, M. Kozako, T. Tanaka and Y. Ohki, Ann. Report Conf. on Elec. Insul. and Dielec. Phenomena, pp. 148-151 (2005).

[7] Filiberto Gonzalez Garcia, Bluma Guenther Soares, Polymer Testing, 22, 51 (2003) [DOI: 10.1016/S0142-9418(02)00048-X].

[8] L. A. Dissado and J. C. Fothergill, Electrical Degradation and
Breakdown in Polymers, G. C. Stevens (ed.), Peter Peregrinus Ltd., London, UK, p. 230 (1992).

[9] R. Widenhorn, M. M. Blouke, A. Weber, A. Rest and E. Bodegom, Proceedings of SPIE, 4669, 193 (2002) [DOI: 10.1117/12.463446].

[10] W. Meyer and H. Neldel, Z. Tech. Phys. 12, 588 (1937).

[11] R. P. Suvarna, K. R. Rao and K. Subbarangaiah, Bull. Mater. Sci., 25, 647 (2002). 